\title{
O CASO DA IGREJA DO BOM SENHOR JESUS DOS MARTÍRIOS E O OLHAR DOCUMENTÁRIO DE ALCIR LACERDA SOBRE A CIDADE DO RECIFE
}

Aryanny Thays da Silva*

Resumo: O presente artigo aborda o olhar documentário sobre a cidade do Recife, produzido entre as décadas de 1960-1980, pelo fotógrafo Alcir Lacerda. As fotografias da destruição da Igreja do Bom Senhor dos Martírios e o debate no cenário político ocorrido na época deste acontecimento são o mote da reflexão que encaminha a escrita, no sentido de historiar as possibilidades de retratar a cidade visualmente e perceber o fotógrafo enquanto sujeito histórico e testemunha ocular. Por último, discute-se ainda a fotografia como exercício de documentar e rememorar.

Palavras-chave: Fotografia. Cidade. Rememorar. Alcir Lacerda.

\section{BOM SENHOR JESUS DOS MARTÍRIOS CHURCH CASE AND THE DOCUMENTARY VIEW OF ALCIR LACERDA ABOUT THE CITY OF RECIFE}

\begin{abstract}
This article approaches the documentary view over the city of Recife, produced between 1960 and 1980, by the photographer Alcir Lacerda. The reflection's motto, which directs the writing in the sense of historicizing the possibilities of visually

\footnotetext{
Đ* Doutoranda em História pela Universidade Federal de Pernambuco. Bolsista da Fundação de Amparo à à Ciência e Tecnologia do Estado de Pernambuco (FACEPE). Integra o Laboratório de História Oral e Imagem da Universidade Federal Fluminense (Labhoi - UFF).
}

$$
\text { VOL. } 3 \quad \text { I N.6 I JUL/DEZ. } 2017
$$




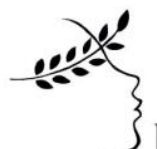

3 FACESDEのIIO $\begin{aligned} & \text { REVISTA DISCENTE DO PROGRAMA DE } \\ & \text { PÓS-GRADUACÃO EM HISTÓRIA - UIFIF }\end{aligned}$

portraying the city and perceive the photographer as a historical subject an eyewitness, is given by the photographs of the Bom Senhor Jesus dos Martírios church's desctruction and the debate in the political scene that took place at the time of this event. Finally, photography is discussed as an exercise of documenting and remembering.

Keywords: City. Photography. Reminisce. Alcir Lacerda.

Um percurso de apropriações sobre a (s) cidade (s) estará presente na trajetória de múltiplos fotógrafos dedicados a registrá-la (s), por isso a necessidade de compreender as dinâmicas em que atuam os sujeitos na construção de representações visuais urbanas. Nesse sentido, historiamos as possibilidades de retratar a cidade, para pensar mais detidamente como o fotógrafo Alcir Lacerda ${ }^{1}$ dispõe o seu olho e vivencia a cidade, os seus espaços e formas.

A primeira observação quando nos deparamos com as imagens que Alcir Lacerda oferece sobre a cidade do Recife ${ }^{2}$ é a raridade da figura humana retratada com proximidade. Contudo, a presença humana anima essas fotografias doutra forma, que não por retratos pousados ou instantâneos. Lacerda, quando visualizamos o conjunto fotográfico sobre Recife, tem uma preocupação especial no registro do corpo arquitetônico da cidade.

Nas suas andanças contempla velhas edificações, novas estruturas, ruas, praças e monumentos que de modo geral contrapõe um Recife que se faz moderno aquele outro dos casarios históricos. Principalmente entre os bairros de São José, Boa Vista, Santo Antônio e Boa Viagem, localizados no centro econômico e cultural dessa cidade, onde podemos notar as principais reformas urbanísticas. Lacerda caminha munido de sua

\footnotetext{
${ }^{1}$ Fotógrafo pernambucano (1927-2012). Ver SILVA, Aryanny Thays da. Prática fotográfica e Experiência social: a trajetória do fotógrafo Alcir Lacerda. Dissertação (mestrado) - Universidade Federal Fluminense, Instituto de Ciências Humanas e Filosofia. Departamento de história, 2015.

${ }^{2}$ Para ter acesso de modo mais amplo a parte da documentação fotográfica do mencionado fotógrafo ver MALTA, Albertina Ótavia Lacerda (org). Alcir Lacerda: fotografia. Recife: Cepe, 2012.
}

$$
\begin{array}{lllll}
\text { VOL. } 3 & \text { N.6 I IULNEZ. } 2017
\end{array}
$$




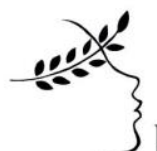

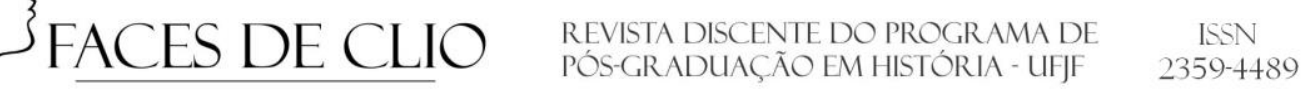

rolleiflex ${ }^{3}$ ou sobrevoa a cidade em pequenos aviões que esquadrinham os contornos da urbe.

A existência humana nesse conjunto fotográfico não se coloca pela presença efetiva na imagem do sujeito no cotidiano de suas atividades, no volver diário de uma grande cidade como era Recife, na segunda metade do século passado. Mas a sua presença é sugerida e inscrita na espacialidade da cidade, porquanto esse espaço seja construído socialmente por meio do intelecto, demandas de poder, ação física e mesmo subjetiva dos homens. Compreende-se que ao olhar as referidas imagens estas significam, por parte do fotógrafo, a consciência do lugar e da presença do homem no espaço urbano.

Interessante que essas fotografias sobre a cidade dialogam com uma noção de arquitetura, que segundo Daniela Mendes Cidade, envolve não "apenas suas construções físicas, mas engloba a forma como ela é recebida pelo sujeito, como ela é vivenciada, como ela é "vista"” (CIDADE, 2002). Essa ideia de vivenciar a cidade fornece elementos para pensarmos de que modo Lacerda realizou esse movimento de interpretação a partir dos dados que a urbe recifense colocava no período que as imagens se materializaram.

Nesse sentido, os registros de Lacerda sobre a Igreja do Bom Senhor dos Martírios $^{4}$ e, por conseguinte da Avenida Dantas Barreto são síntese para pensar essa cidade que se transformava para o futuro. Antes de mencionarmos a discussão em torno da destruição dessa igreja, vale mencionar que Lacerda acompanhou todo esse processo que se estendeu desde o ano de 1943, quando o urbanista Ulhôa Cintra ${ }^{5}$ desenhou planos

\footnotetext{
${ }^{3}$ Linha de câmeras fotográficas de uso profissional fabricadas pela empresa alemã Franke \& Heidecke, hoje denominada Rollei $\mathrm{GmbH}$.

${ }^{4}$ A Igreja do Bom Senhor Jesus dos Martírios teve seu templo construído entre os anos de 1791-1796, enquanto a irmandade fundadora dessa igreja havia sido instituída em 1773, na matriz de Nossa Senhora do Rosário da Vila do Recife, sendo constituída por homens pretos e crioulos. Seu templo foi o único no Brasil completamente construído por mãos escravas e teve um importante papel, pois esta irmandade mantinha atividades "secretas" em favor da abolição, como a arrecadação de fundos que através das Juntas de Alforrias auxiliam os negros em suas lutas pela liberdade.

${ }^{5}$ João Florence D’Ulhôa Cintra (1887-1944), engenheiro civil pela Escola Politécnica de São Paulo. Foi diretor de obras do município de São Paulo, quando em 1943 foi convidado pela Comissão de Plano da Cidade do Recife para elaborar um plano geral que previa a remodelação e expansão do Recife. Assim
}

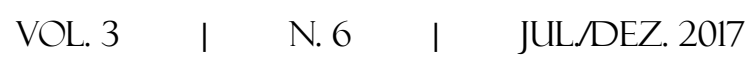




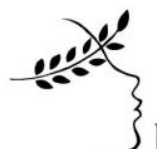

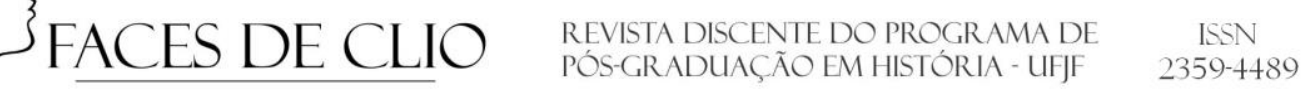

para a remodelação e expansão do Recife, com a previsão da abertura da Avenida Dantas Barreto, até chegarmos a 1973, ano em que, com algumas modificações no plano original, a avenida foi inaugurada.

A Acê Filmes, agência fundada por Lacerda, encontrava-se instalada desde a década de 1950 no Edifício Inalmar, no décimo primeiro andar, localizado na Avenida Dantas Barreto. Esse fato implicou elementos importantes na trajetória do fotógrafo: este se habitou a ver a cidade do alto, e nesse sentido, tinha uma vista privilegiada dos arredores do centro da cidade devido à localização do edifício mencionado ${ }^{6}$.

Em decorrência disso Lacerda acompanhou de maneira distinta as mudanças operadas para a construção desta via em particular. Como o fotógrafo passava grande parte de seu tempo nesse prédio pôde observar a descaracterização ao longo das décadas do entorno mencionado. Nessa perspectiva é que a destruição de Martírios se torna tão emblemática no conjunto de fotografias feita por este fotógrafo sobre a cidade do Recife.

Em entrevista à pesquisadora e autora deste artigo, a filha do fotógrafo comentou sobre as vivências de Lacerda em ver a cidade do alto, a partir do Edifício Inalmar, e sua relação com as imagens sobre Martírios:

ele se envolveu muito, ele trabalhava e passava todo o dia de manhã até seis horas, sete horas da noite naquele centro, dentro do Inalmar, que é na Avenida Dantas Barreto. Então ele via dali do décimo primeiro andar... ele acostumouse muito a ver o Recife do alto. Apesar de andar muito pelo centro você percebe esse certo distanciamento dele, entre aspas, da visão dele como fotógrafo. Eu percebo muito do gosto dele de ver a cidade do alto, como se ele quisesse abraçar a cidade, dominar a cidade como um todo. ${ }^{7}$

Os verbos abraçar/dominar que Albertina Lacerda usa para caracterizar a fotografia aérea de seu pai são significantes, pois colocam ao fotógrafo a apreensão de um espaço muito mais extenso do que aquele oferecido enquanto se caminha pela

sugeriu mudanças para a estrutura viária, ao esquema de transporte ferroviário, reconfigurações das áreas centrais (espacialmente os Bairros de São José e Santo Antônio) e à expansão do Porto.

${ }^{6} \mathrm{O}$ edifício se encontrava (e ainda está) localizado na parte já construída da avenida que durou, entre todo o processo, cerca de trinta anos até ficar definitivamente pronta.

${ }^{7}$ Entrevista com Albertina Lacerda concedida a Aryanny Thays da Silva em dezembro de 2014, 32m16s.

$$
\begin{array}{lllll}
\text { VOL.3 I } & \text { N.6 } & \text { I JUL/DEZ. } 2017
\end{array}
$$




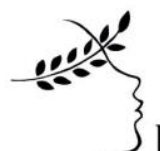

JFA@ESDECIIO $\begin{aligned} & \text { REVISTA DISCENTE DO PROGRAMA DE } \\ & \text { PÓS-GRADUACÃO EM HISTÓRIA - UIFJF }\end{aligned}$

cidade. O fotógrafo inscreve sobre a cidade recortes que são mediados por escolhas e acabam por traçar e construir limites sobre o que é visualizado e decodificado por outros.

Nesse sentido, esmiuçando as possibilidades de significados dos verbos acima, essas fotografias mostram o domínio do fotógrafo acerca do meio técnico, assim como do espaço urbano e da natureza por meio de aparatos tecnológicos da modernidade. Lacerda então, expõe novos quadros temporais produzidos e alimentados por objetos do século XX, tal como os aviões. Compreendido este lugar de atuação do fotógrafo abordaremos a seguir um breve apanhado para situar os registros fotográficos de que falamos.

Em 1946, três anos após a aprovação do plano urbanístico que previa a construção da Avenida Dantas Barreto e consequentemente a destruição do Pátio do Carmo e de São Pedro ${ }^{8}$, visões antagônicas já estimulavam os debates no seio dos interesses preservacionistas. Os jornais também noticiavam a questão que aparecia sob a visão oposta do velho e do novo, além de reflexões sobre a real necessidade da destruição da malha urbana histórica existente, tendo em vista outras problemáticas urbano-sociais mais prementes.

Assim, foi realizada uma remodelação no plano original, que tirou da rota o Pátio de São Pedro e do Carmo, mas passou a inserir a Igreja dos Martírios no novo traçado da avenida a ser construída, o que acarretaria sua destruição. Nesse ínterim permaneceram as discussões em torno da viabilidade e relevância dessa avenida, já que na década de 1950, com a construção de outra grande avenida (Agamenon Magalhães) ${ }^{9}$, supunha-se que o problema viário de interligação norte-sul estivesse resolvido.

No ano de 1959, a construção da avenida foi interrompida na altura do Pátio do Carmo e assim permaneceu por alguns anos. Entretanto, em 1964, na primeira gestão de

\footnotetext{
${ }^{8}$ Onde se localizam, respectivamente: os conjuntos arquitetônicos da Igreja de Nossa Senhora do Carmo e do Convento do Carmo (Bairro de Santo Antônio) e a Igreja de São Pedro dos Clérigos (Bairro de São José), formada pela irmandade do mesmo nome. Ambas foram instituídas Patrimônio Histórico e Artístico Nacional em 1938.

${ }^{9}$ Também idealizada pelo arquiteto Ulhôa Cintra.
}

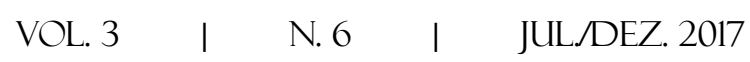




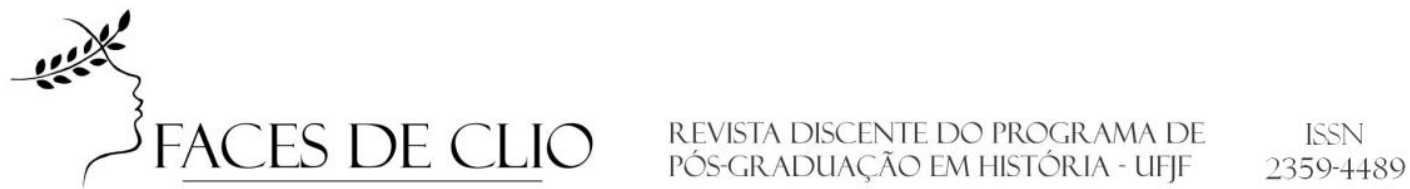

Augusto Lucena, que assumiu a prefeitura do Recife após o golpe militar daquele ano ${ }^{10}$, foram retomadas as discussões para concretização da Avenida Dantas Barreto.

Contudo, nesse instante, os intelectuais recifenses passaram a expressar sugestões, críticas e uma presença marcante no cenário das discussões efetuadas sobre Martírios. Inspirados pela ampliação da noção de monumento histórico que possibilitou que edifícios precariamente valorizados em termos de relevância histórico-cultural pudessem ser alçados ao interesse da permanência e preservação. Também a maior flexibilidade nas atividades desenvolvidas pelo $1^{\circ}$ distrito do Serviço de Patrimônio Histórico e Artístico em Pernambuco possibilitou que ações em favor da permanência da Igreja dos Martírios fossem articuladas.

A Irmandade do Senhor Bom Jesus dos Martírios passou a dialogar com este órgão e outros na tentativa de reverter o quadro apresentado ${ }^{11}$. Havia por parte desses grupos de defesa da igreja uma crítica formulada a ideia de progresso tão cara ao Brasil no período, dada às propostas desenvolvimentistas em voga, notadamente em relação às transformações urbanas.

As ideias preservacionistas foram se fortalecendo a partir dos diversos enunciados e discursos na medida em que partiam de lugares de fala especializados sendo assimilados por diferentes segmentos profissionais. Segundo Rosane Loretto, essa assimilação "foi responsável pela capilarização desse ideário, fazendo-o espalhar por grande parte da cidade, que cada vez mais se politizava em relação à questão da destruição da igreja" (LORETTO, 2008, p. 168).

No entanto, no final da década de 1960, e com a saída do prefeito Augusto Lucena do poder em 1968, as discussões em torno da destruição definitiva da igreja

\footnotetext{
${ }^{10}$ Augusto Lucena assumiu a Prefeitura do Recife após o afastamento de Pelópidas Siveira, então prefeito da cidade. Seu primeiro mandato durou entre 1964-1968. Nesse período, filiou-se a Aliança Renovadora Nacional (ARENA).

${ }^{11}$ Entre eles, pode-se destacar o Instituto Arqueológico e Histórico de Pernambuco, a Academia Pernambucana de Letras, do curso de Arquitetura da Universidade Federal de Pernambuco e do Conselho Estadual de Cultura, que contava com figuras como Lula Cardoso Ayres (artista); João Cabral de Melo Neto (escritor); Mauro Mota (poeta); Mário Lacerda (geografo), entre outros.
}

$$
\begin{array}{lllll}
\text { VOL. } 3 & \text { N.6 I IULNEZ. } 2017
\end{array}
$$




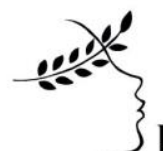

$\begin{array}{lll}\text { FACES DE CLIO } & \begin{array}{l}\text { REVISTA DISCENTE DO PROGRAMA DE } \\ \text { PÓS-GRADUACÃO EM HISTORIA-UFJF }\end{array} & \text { ISSN } \\ 2359-4+89\end{array}$

desaceleraram. Na chefia da municipalidade do Recife assumiu Geraldo Magalhães ${ }^{12}$, que teve por prioridade administrativa e urbanística obras como os viadutos da Avenida João de Barros e do Forte de Cinco Pontas, entre outras ${ }^{13}$. O próprio prefeito pediu que fosse elaborado um plano alternativo que pudesse preservar Martírios, devido aos vários apelos que estavam em cena. Assim, o escritório técnico de planejamento da prefeitura elaborou uma proposta que permitiria a preservação do templo e do endereço que o abrigava, a Rua Augusta.

Mas no ritmo das profundas mudanças que caracterizavam o domínio político no contexto da ditadura militar, em 1971 houve o retorno de Augusto Lucena à prefeitura da cidade. Segundo informa Loretto, nesse instante aconteceu o "acirramento do debate sobre o destino do templo"14, tanto no âmbito institucional como na esfera urbanística. Os sujeitos envolvidos passaram a um embate mais caloroso, pois Lucena não levou a frente o projeto que deixaria a Igreja dos Martírios intacta.

Desse modo, entre 1971-1975 uma série de querelas, invenções e desmandos políticos mobilizaram a cena pernambucana. Em meio à iminência da demolição de Martírios e a concretização da Avenida Dantas Barreto, houve ações que tentaram desmobilizar a luta pela permanência da igreja, como a fala vinculada pela imprensa que informava da possibilidade de desabamento do templo, quando o próprio IPHAN havia emitido um parecer que afirmava as condições estáveis da construção citada.

Também a própria prefeitura da cidade do Recife fez coro à ameaça de desabamento da igreja, pedindo que o seu processo de tombamento da mesma, conduzido pelo IPHAN, fosse anulado. Lucena encontrava-se bastante empenhado em levar à frente seus planos de construção da avenida em questão, e nesse sentido, não resguardou esforços para consegui-los. Colocou em dúvidas a idoneidade do IPHAN, como instituto técnico e especializado, ao mesmo tempo em que sugeria interesses

\footnotetext{
${ }^{12}$ Formado em engenharia civil e sobrinho de Agamenon Magalhães, ex-interventor e ex-governador de Pernambuco. Geraldo Magalhães exerceu o cargo de prefeito entre 1969-1971.

${ }^{13}$ Junto com outras obras de intervenção urbanas, essas construções geridas no governo de Magalhães continuavam a embalar a ideia de desenvolvimento e mobilidade para a capital pernambucana naquele momento.

${ }^{14}$ LORETTO, Paraíso e Martírios, op. cit., p. 179.
}

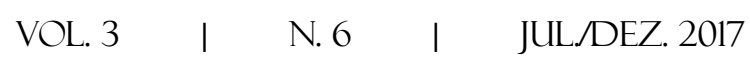




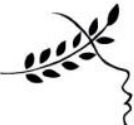

$\begin{array}{ll}\text { FACES DE CLIO } & \begin{array}{l}\text { REVISTA DISCENTE DO PROGRAMA DE } \\ \text { Pós-GRADUAÇÃo EM HISTÓRIA- UFJF }\end{array} \\ \text { ISSN } \\ \text { 2359-4t89 }\end{array}$

escusos por parte desse órgão na manutenção da Igreja dos Martírios. A atuação do IPHAN como instituição que geria aquele bem histórico passou a ser vista pela prefeitura como uma afronta ao governo militar instaurado e que pretendia enfraquecê10. ${ }^{15}$

A ideia desse possível "ato conspiratório" contra o regime se estendeu e após o tombamento da igreja, o prefeito da cidade do Recife reuniu-se com seus secretários para articular um argumento que pudesse reverter à situação. Posteriormente, a prefeitura uniu-se a Associação dos Incorporadores de Pernambuco ${ }^{16}$, tal junção prenunciava os interesses que moviam a municipalidade, e que foram escritos numa carta ao Ministro da Educação e Cultura, Jarbas Passarinho ${ }^{17}$, pedindo uma solução ao caso em questão.

\footnotetext{
${ }^{15}$ Ver LORETTO, Paraíso e Martírios, op. cit.

${ }^{16} \mathrm{~A}$ relação entre essa associação e poder municipal significam do valor especulativo imobiliário que havia naquela área de construção da Avenida Dantas Barreto.

${ }^{17}$ Nasceu em Xapuri, Acre, 1920. Militar e político brasileiro.
}

$\begin{array}{lllll}\text { VOL. } 3 & \text { N.6 I JU/DEZ. } 2017\end{array}$ 

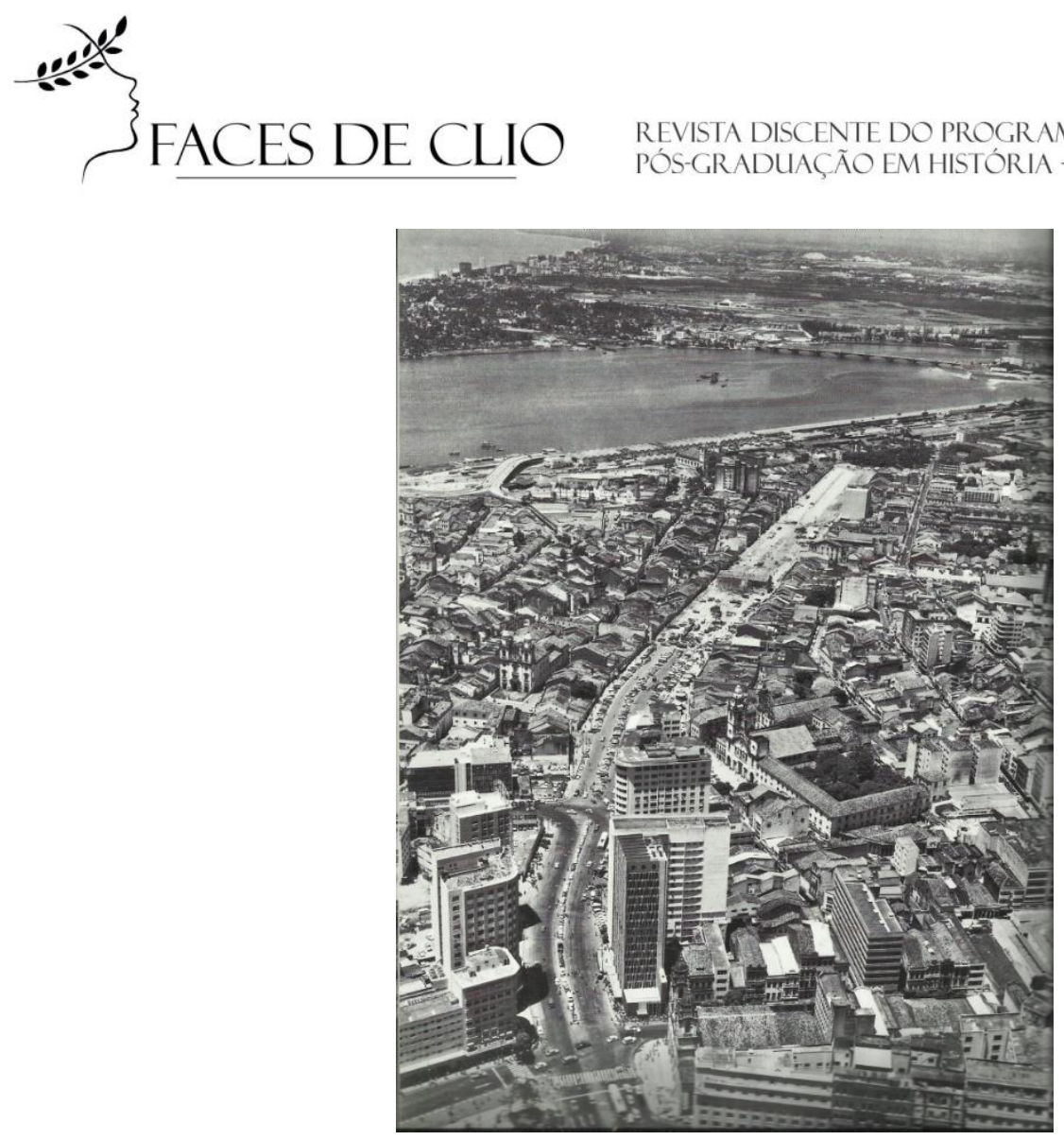

Figura 1 - Abertura da Av. Dantas Barreto, conjunto arquitetônico do Carmo, Igreja de São Pedro dos Clérigos, Igreja dos Martírios, ainda de pé no meio da avenida, 1973, Alcir Lacerda.

As tensões prosseguiram efetivamente até que a decisão ficou a cargo do presidente do país naquele momento, o General Médici. Este acabou por autorizar o destombamento da Igreja dos Martírios em um documento assinado por ele e pelo já citado ministro da Educação e Cultura. Este fato ocorreu já em 1972 e acabou por desmobilizar as forças que se moviam a favor da igreja, assim como a própria irmandade. Apesar da morte anunciada a igreja sobreviveu ainda até janeiro de 1973, quando foi noticiado que sua demolição ocorreria em 12 de janeiro. ${ }^{18}$ Foi terminantemente destruída no dia 28, como noticiou o Diário Oficial do Município do Recife daquele mês. Oito meses depois, em setembro de 1973, a Avenida Dantas Barreto foi inaugurada com a presença de várias autoridades.

\footnotetext{
${ }^{18}$ A destruição da Igreja dos Martírios e seu entorno também foi fotografada com mais proximidade em relação aos objetos por Wilson Carneiro da Cunha.
}

$$
\begin{array}{lllll}
\text { VOL.3 I N.6 I JU.DEZ. } 2017 &
\end{array}
$$



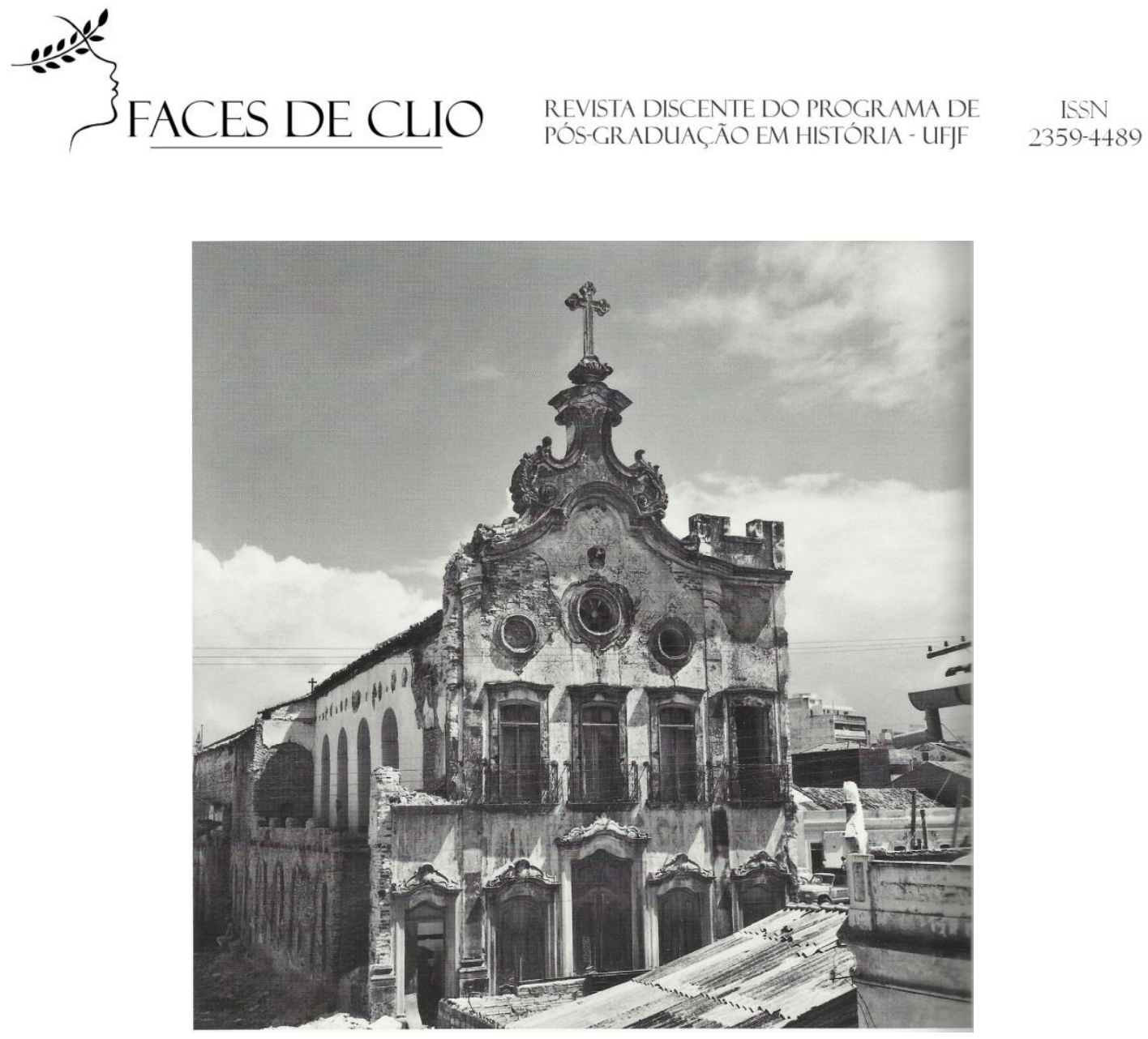

Esse quadro resumido apresenta os conflitos caracterizadores pela abertura de uma larga e longa avenida em contraposição a preservação da Igreja dos Martírios, que passou a simbolizar o ponto alto das discussões sobre as práticas urbanísticas no Recife, que desde a década de 1930 vivenciava um ciclo arquitetônico que introduziu, consolidou e desenvolveu o pensamento moderno nesta cidade. ${ }^{19}$

Este processo não se fez sem tensões, com maior ou menor densidade, conforme corriam as três décadas que levou para concretizar-se. Percebemos que a construção histórica em torno deste evento envolveu vários atores sociais, entre políticos, intelectuais, especialistas em preservação do patrimônio, o núcleo religioso e por fim, também os cidadãos comuns, das cercanias dos bairros em reformas, e aqueles que foram desalojados quando diversos casarios e ruelas foram abaixo.

\footnotetext{
${ }^{19}$ Ver AMORIM, Luiz. Obituário arquitetônico: Pernambuco Modernista. Recife: Editora UFPE, 2007.
}

$$
\text { VOL.3 I N.6 I JUL/DEZ. } 2017
$$




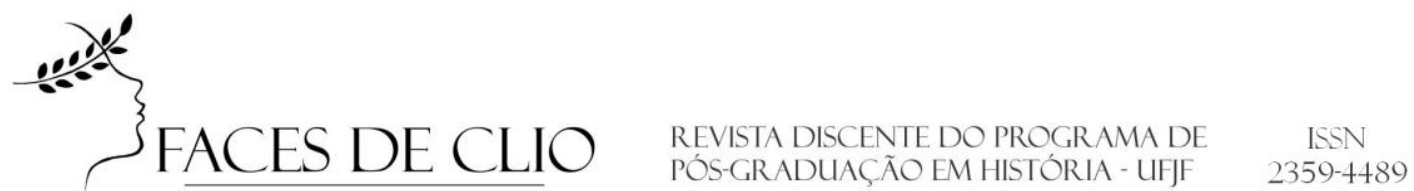

Alcir Lacerda e sua fotografia ocupam um duplo lugar nesse contexto: por um lado a afirmação da presença do sujeito enquanto testemunha ocular no desenrolar dos acontecimentos, e por outro lado, a sua fotografia como extensão da sua presença na cidade. $\mathrm{O}$ ato fotográfico se relaciona como a percepção do sujeito fotógrafo que se insere no espaço urbano e o organiza no visor de sua máquina fotográfica.

Quando nos deparamos com estas imagens no decorrer da pesquisa - a série representativa sobre a cidade do Recife -, perguntávamos qual interesse, ou questão, movia o olhar de Lacerda e seu cuidado em documentar esta cidade ao longo de tanto tempo. O conjunto de fotografias tematizavam a cidade dando a ver alguns subtemas específicos: construções arquitetônicas e paisagísticas, acompanhamento de reformas urbanísticas, vistas aéreas do espaço social. Em menor número representativo víamos algumas experimentações de Lacerda na fotografia: lente olho de peixe, uso do obturador em baixa velocidade. Porém, em todas essas o Recife era visto no trânsito entre o tornasse moderno e o embate preservacionista que movia a sociedade naquele período.

A própria demolição da Igreja de Martírios causou espanto em Lacerda que acompanhava a construção da Avenida Dantas Barreto no correr das décadas. Em uma das várias entrevistas que forneceu durante sua trajetória falou sobre Martírios:

Eu comecei acompanhando a abertura da Av. Dantas Barreto, fazendo umas fotos aéreas. Aí, eu pensei, a igrejinha deve ficar no meio da rua igual à Candelária, lá no Rio de Janeiro... foi então que me avisaram que estavam botando abaixo a igreja, cheguei bem cedinho e consegui fazer uma parte dela em pé ainda, a frente, os lados e as costas. No entanto, na calada da noite, derrubaram Martírios. ${ }^{20}$

A expressão final da fala do fotógrafo exemplifica o tom dos embates que giravam na cidade. Para Lacerda, de acordo com sua fala, o mais indicado teria sido a manutenção da igreja, com a opção alternativa de desviar a via, tal qual a Igreja da Candelária que ele conhecia no Rio de Janeiro, que circunda a Avenida Presidente

\footnotetext{
${ }^{20}$ Depoimento de Alcir Lacerda presente no livro MALTA, Albertina Ótavia Lacerda (org). Alcir Lacerda: fotografia. Recife: Cepe, 2012.

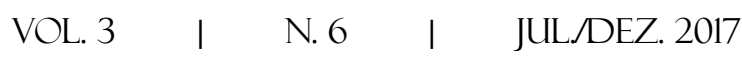




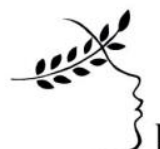

$\operatorname{Vargas}^{21}$. Contudo, vários projetos alternativos haviam sido pensados para a permanência de Martírios, porém nenhum chegou a ser levado à execução. E mesmo as vozes insatisfeitas da população não foram consideradas.

Nesse sentido, as fotografias de Lacerda que tratam da derrubada da igreja documentam a sobreposição da vontade política no que diz respeito ao destino dos monumentos. Encontram-se atravessados nestes registros à experiência do fotógrafo e a trajetória da cidade, que se imbricam na medida em que a fotografia materializa uma série de escolhas realizadas pelo sujeito fotógrafo.

$\mathrm{Na}$ série analisada são quatro fotografias que retratam a temática que envolve a Igreja dos Martírios. Em uma das fotografias vemos a igreja retratada em diagonal, já sem a sua torre (figura 2). Noutra imagem vemos a Avenida Dantas Barreto já finalizada em 1974, sem a igreja que atravancava seu caminho. E por fim, a última fotografia, que consideramos a mais simbólica dentre as citadas, pois apresenta a igreja ainda em pé, solitária, na amplidão de uma avenida que a todo custo queria-se pronta (figura 1).

A força dessa fotografia se coloca principalmente quando a inserimos em uma linha do tempo contemporânea em que seu uso e suas funções são ressaltados. Não pela pretensão de esvaziar o significado do instante de sua feitura, pois embora não saibamos das circulações desse registro naqueles anos entre 1973-1974, acreditamos que esta materialize as novas caracterizações da cidade do Recife, tornando-se uma foto-ícone que condensa um acontecimento no tempo.

Ao longo das últimas décadas, especialmente, a Igreja dos Martírios tem sido ponto de reflexão sobre a urbanização no Recife. Nesse contexto, a fotografia de Lacerda surge como sintetizadora desse processo que marcou profundamente a memória

\footnotetext{
${ }^{21}$ Ao que parece Lacerda não sabia das profundas transformações que deram lugar para a abertura da Avenida Presidente Vargas no Rio de Janeiro. A sua construção, realizada durante o Estado Novo, por iniciativa de Getúlio Vargas, colocou abaixo mais de mil imóveis. Alterando de modo brutal o traçado urbano do centro do Rio. A obra que levou três anos para ficar pronta levou à demolição vários conjuntos arquitetônicos importantes, como as igrejas de São Domingos, 1791; de Bom Jesus do Calvário, 1719; de Nossa Senhora da Conceição, 1757; e a de São Pedro dos Clérigos que era considerada uma pérola do barraco e se encontrava também no meio da passagem da nova avenida. A única construção que resistiu a essa série de destruições foi a Igreja de Nossa Senhora da Candelária que teve sua grandiosidade adequada ao projeto modernizante.
}

$\begin{array}{lllll}\text { VOL. } 3 & \text { N.6 } & \text { JULADEZ } 2017\end{array}$ 


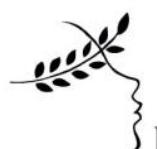

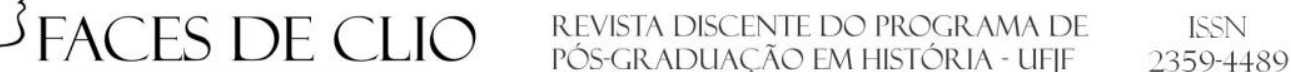

e a malha da cidade como uma espécie de cicatriz que expressa dos desmandos e autoritarismos vividos na década de 1970.

Enquanto foto-ícone que, segundo Mauad, se distinguem como aquelas que "ganham expressões públicas, associadas, ao mundo da política e a noção de acontecimento histórico" (MAUAD, 2008), a figura 1 mobiliza esses dois aspectos acima. Pois por um lado encerra debates em torno da cidade a partir da participação política de diversos atores na cena social. Por outro lado, os processos de rememoração atuais acabaram por projetar estas fotografias do evento estudado como um dos gatilhos que deflagram as discussões em volta das reformas urbanísticas na cidade do Recife. De modo que o registro fotográfico passou a simbolizar o evento e a participar das reconstruções do acontecimento na contemporaneidade.

\section{A fotografia como exercício de documentar e rememorar}

Essa documentação fotográfica nos remete a pensar a fotografia enquanto um exercício de documentação e rememoração ${ }^{22}$ no contexto das reflexões empreendidas sobre a imagem fotográfica na experiência histórica contemporânea. Respondendo a demandas das conjunturas históricas em que foram gestadas, como também a questões do presente, que podem envolver políticas de acervo, processos institucionais e ressignificações da memória, ao longo de seus circuitos sociais.

A função documental da fotografia a acompanha desde o seu nascimento, quando se percebeu seu potencial de registro dos acontecimentos e sujeitos nos mais diversos cantos do mundo. A imagem fotográfica foi objeto de fascínio e conhecimento, que permitiu a assimilação de costumes, estudos de caráter científico, técnico, além da circulação de retratos e paisagem enquanto objetos exóticos de consumo. Nesse

\footnotetext{
${ }^{22}$ Reflexão surgida a partir da leitura do artigo publicado na Revista Continente, dez-2012, intitulado "Exercício de documento, memória e identidade", de José Afonso Silva Junior, sobre o então livro Alcir Lacerda - fotografia que havia sido lançado recentemente.
}

\begin{tabular}{l|lll} 
VOL. 3 & N.6 I IL/DEZ. 2017
\end{tabular} 


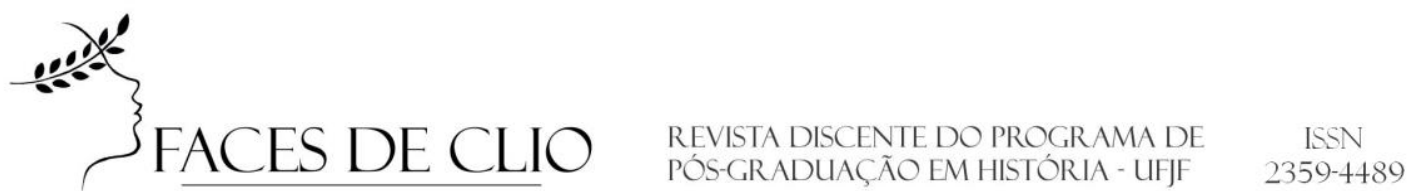

momento, a fotografia era compreendida como prova, registro direto do referente sobre o suporte, como lembra Rouilléér.

Ao longo do último século e meio de existência do artefato fotográfico o seu aspecto documental foi-se transformando. A maneira de registrar ganhou nuances que variavam respondendo aos regimes visuais de épocas distintas. Percebemos que na fotografia realizada por Lacerda existe uma preocupação documental em registrar o evento, materializa-lo no suporte fílmico e preservá-lo. O fotógrafo dimensiona seu olhar e exercita sua sensibilidade fotografando temas de seu interesse.

A série sobre a cidade do Recife explicita o apuro na técnica de Lacerda na composição de bons quadros, e no uso da luz. Porém, ultrapassa as regras da boa composição, e se qualifica pelo esmero em termos individuais em documentar material e afetivamente a cidade em que vive. Se entendermos que o fotógrafo constrói representações sobre a urbe, e por outro lado também à cidade, em todos seus aspectos, oferece elos que dão sentido à existência dos sujeitos, temos aí um duplo movimento que implica em um exercício de documentar e tecer narrativas visuais.

A cidade é então um lugar onde uma série de narrativas em trânsito tornam-se visíveis e cuja tessitura é mediada pelo olhar do fotógrafo. No contexto do fotodocumentarismo, a documentação fotográfica sobre o Recife resulta do interesse de Lacerda em preservar imagens para a posteridade, como se estivesse ciente que a memória da cidade decorre de escolhas, recortes e esquecimentos.

Para a prática historiográfica, faz-se menção a Le Goff (1996), e seu conceito de documento/monumento ${ }^{24}$. Considerando o ato fotográfico como um exercício de documentar e construir representações por parte do fotógrafo, a função documental da fotografia se efetua, assim como qualquer outro documento, no campo da História, pela compreensão que esta é uma operação de escolhas realizadas pelas sociedades passadas ou ainda pelo ofício do historiador dedicado ao seu estudo.

\footnotetext{
${ }^{23}$ ROUILLÉ, ANDRÉ. A fotografia entre documento e arte contemporânea. Tradução Constância Egrejas. São Paulo: Editora Senac, 2009.

${ }^{24}$ LE GOFF, Jacques. História e memória. 4.ed. Campinas: Editora da Unicamp, 1996.
}

$$
\text { VOL.3 I N.6 I JUL/DEZ. } 2017
$$




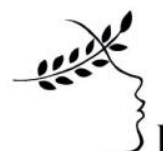

FACES DE CLIO
PÉS-GRADUACÃO EM HISTÓRIA - UFJF

Avançando nos debates dicotômicos que separavam as noções de documento e monumento, Le Goff defende que todo documento é monumento, pois este seria fruto de intenções e escolhas de sujeitos no tempo. Nesse sentido, o exercício de Lacerda em documentar a cidade, pressupõe ao pesquisador o entendimento do artefato fotografia enquanto documento/monumento. De acordo com Mauad, a imagem/documento se remete ao índice "como marca de uma materialidade, na qual objetos, pessoas, lugares nos informam sobre determinados aspectos do passado" e já a imagem/monumento "é um símbolo, aquilo que no passado a sociedade estabeleceu como a única imagem a ser perenizada para o futuro". 25

Posto que seja pensada assim, a fotografia documento/monumento deve ser trabalhada a partir dos seus circuitos sociais - produção, consumo e circulação da imagem fotográfica. No caso das fotografias aqui mencionadas sabe-se que estiveram por algum tempo restritas ao acervo pessoal do fotógrafo, numa rede que privilegiava família, amigos e os particularmente interessados em fotografia. Porém, algumas exposições a partir dos anos 2000, esse quadro começou a mudar. Dentre elas, a exposição Alcir Lacerda - fotografia, que teve por objetivo uma retrospectiva de toda sua obra até o ano de 2004, quando teve lugar na Torre Malakoff, em Recife.

Como a fotografia decorre da atividade de investimento de sentido primeiro realizada pelo fotógrafo, também novas apropriações no contexto de montagens expográficas, organizações de acervos/arquivos, requerem um trabalho nesse mesmo rumo, o que acaba por imprimir novas configurações e significados aqueles pretendido pelo fotógrafo.

Desse modo, para além do exercício de documentar o mundo visualmente, a fotografia remete igualmente a processos de rememoração. Podemos imaginar que muitos álbuns de família reúnam registros desse tipo, pois há sempre no instante do ato fotográfico a ideia de guardar aquela imagem para que se possa de algum modo reter o vivido. Essa fotografia é então produzida com a intenção de memória, e ao longo do

\footnotetext{
${ }^{25}$ MAUAD, Ana Maria. Poses e Flagrantes: Ensaios sobre História e Fotografia. Niterói: Editora da UFF, 2008, p. 37.
}

$$
\begin{array}{lllll}
\text { VOL. } 3 & \text { N.6 I IULNEZ. } 2017
\end{array}
$$




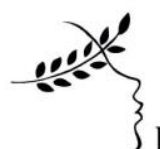

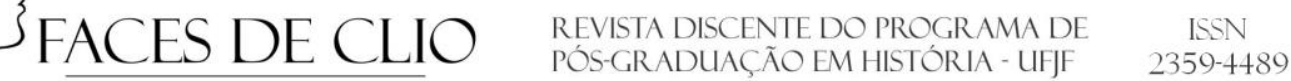

tempo desempenha tal função ao proporcionar o trabalho de rememoração, a partir de reminiscências projetadas pelo registro fotográfico.

Mas também, as fotografias podem ser instituídas como lugares de memória, seguindo a ideia de Pierre Nora $^{26}$, em texto já clássico. Essa compreensão ressalta o papel ativo dos arquivos, museus, e celebrações para a fotografia enquanto um objeto de rememoração. Sendo a memória um fenômeno sempre atual, as fotografias nesse argumento são ressignificadas de acordo com os interesses que movem esses ditos lugares de memória.

Algumas das fotografias de Alcir Lacerda discutidas acima, por exemplo, têm sido vivenciadas como exercício de rememorar por diversos atores na contemporaneidade que se ocupam em tornar visível a cidade do Recife por meio dessas imagens, ao mesmo tempo em que elaboram novas formas de conhecer e imaginar a cidade. Adotando a fotografia como uma mensagem elaborada no tempo, tendo em perspectiva as exposições que tiveram lugar após a morte de Lacerda no ano de 21012 vê-se como seus registros foram apropriados para delinear uma cidade que já não existe se não visualizada nestas imagens.

Logo, as fotografias de Lacerda sobre a cidade do Recife nos permitem esboçar alguns apontamentos. Primeiramente que a memória supõe o esquecimento, não só no que diz respeito aos processos de rememoração instigados através do ato de olhar fotografias, mas a própria atividade do fotógrafo que encerra no visor de sua câmera certos conteúdos ao mesmo passo que exclui outros.

Nessas fotografias realizadas por Alcir Lacerda percebemos que de algum modo na urbe pressupõe-se a necessidade da destruição para construir-se o novo. De modo geral, esses processos de transformações urbanas que puseram abaixo ruas, becos, edifícios históricos ocorreu em diversas cidades no Brasil e no mundo, e grande parte delas foi registrada pelas lentes atentas de fotógrafos atuando livremente ou a serviço

\footnotetext{
${ }^{26}$ NORA, Pierre. Entre memória e história: a problemática dos lugares. Projeto História, n.10, p. 7-28, 1993.
}

\begin{tabular}{l|lll} 
VOL. 3 & N.6 I IL/DEZ. 2017
\end{tabular} 


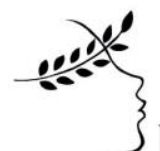

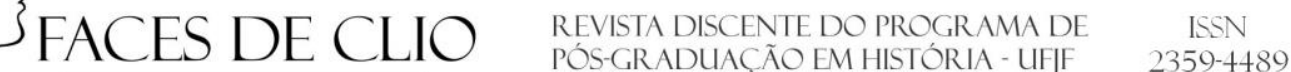

dos Estados. Nesse sentido, interessa como a fotografia documenta e ativa reminiscência sobre a cidade que retrata.

Em Lacerda e nas imagens trabalhadas nota-se o entrelaçamento de temporalidades inscritas no espaço urbano, especialmente pela convivência entre os velhos casarios e os novos ambientes de habitar moderno. A fala do arquiteto Luiz Amorim caracteriza consistentemente essa documentação fotográfica:

\begin{abstract}
observados em diacronia, os registros de Alcir Lacerda contam a gradual transição do Recife de feições lusitanas - seus sobrados, conventos e adros, para um cenário que reflete sua progressiva modernização e consolidação da expressão modernista em seus traçados urbanos e edilícios (AMORIM, 2012, p.22).
\end{abstract}

A arquitetura, que insistimos em assinalar enquanto espaço de intervenção e apropriação dos homens, remete a elos de coesão social no espaço e no tempo, assumindo a partir dos processos de rememoração retornos ao passado com tons ora saudosistas, ora críticos, a depender das intenções de quem o faz. O registro da Igreja de Martírios ainda em pé na extensão da Avenida Dantas Barreto é emblemático nessa conjuntura.

Da maneira que entendemos, estas imagens possuem um valor significativo nos embates da memória, pois reúnem manifestações humanas simbolizadas e abrigadas no corpo arquitetônico da cidade que se transformava. Essas fotografias retratam um Recife que muitos não reconhecem, e se "as cidades são feitas de martírios e nascimentos," 27 nos debates atuais, caros a dinâmica da urbe recifense, um caráter melancólico e crítico fazem lembrar essas fotografias.

Sendo a dimensão do presente que coloca questões a prática do historiador, e se não partimos da premissa falha que as fontes possam resgatar um passado tal qual ele foi, percebemos que estas fotografias e a atividade de memória por elas suscitadas estão atravessadas no tempo presente por demandas urbanísticas em discussão no Recife. As destruições de conjuntos arquitetônicos coloniais e modernos para a construção de edifícios espigões e a utilização dos espaços públicos regidos pela ótica do ${ }^{27}$ Idem.

\begin{tabular}{l|lll} 
VOL. 3 & N.6 I IL/DEZ. 2017
\end{tabular} 


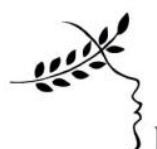

3 FACESDECLIO $\begin{aligned} & \text { REVISTA DISCENTE DO PROGRAMA DE } \\ & \text { PÓS-GRADUACÃO EM HISTÓRIA - UIFIF }\end{aligned}$

empreendedorismo excludente são apenas alguns exemplos atuais. Essas questões remetem a polêmica destruição de Martírios, e encadeiam uma reflexão sobre a cidade e as formas possíveis de habitá-la.

Se voltarmos a ideia que a cidade pressupõe a destruição para a construção do novo, ou ainda, caso sigamos as reflexões de Amorim, sobre a noção de morte anunciada na arquitetura das cidades:

\begin{abstract}
Anunciada nas normas dos homens, que estabelecem o princípio de que trocar uma arquitetura por outra é um bom negócio. Anunciada, seu nome próprio, é sempre cega, surda e muda, mas sempre fala, ouve e vê. (...) é conhecida pelas alcunhas do progresso, demanda habitacional, ou, simplesmente, investimento imobiliário. ${ }^{28}$
\end{abstract}

Os embates em torno da Igreja de Martírios se desdobraram até o início de 1970 e todos os três temas citados na fala figuram nesse processo de urbanização. Se a questão dessa igreja e da própria cidade tem sido motivo de retornos e reconstruções pelo trabalho da memória é que o passado tem sido problematizado a partir de demandas vivenciadas no presente. Interessante ressaltar que nesse sentido a fotografia enseja um triplo exercício de documentar; rememorar e de identidade.

Este último ponto - a identidade - como elemento de construção de si, para si e para os outros. Partindo da ideia que a cidade seja um lócus de coesão social onde os homens se inserem e organizam-se, onde opera memória como constituinte do sentimento de identidade. Nessa documentação fotográfica que trabalhamos percebemos redes intrincadas entre os processos de rememoração engatilhados pelas imagens e a afirmação de identidades ligadas à cidade.

Nesta trilha aberta podemos citar o documentário produzido por Mariana Lacerda, Pausas Silenciosas. A partir do encontro da cineasta com a fotografia da Igreja de Martírios, no acervo iconográfico da Fundaj (Fundação Joaquim Nabuco), iniciou-se uma série de reflexões empreendidas pela autora que, entre outras coisas, evidenciou a cidade do Recife e as transformações ocorridas nela. De modo que a fotografia em

\footnotetext{
${ }^{28}$ AMORIM, Obituário arquitetônico, op. cit.
}

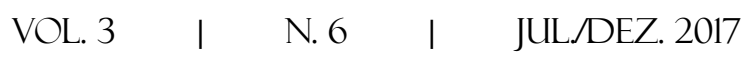




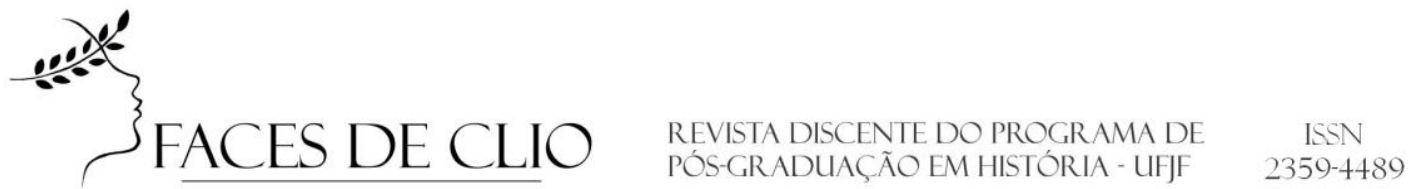

questão deflagrou o gatinho da memória da cineasta que é recifense por nascimento, mas já não vive na cidade há alguns anos.

Recapitulando: uma fotografia de arquivo sobre cidade, de um acontecimento urbanístico importante, é localizada por um sujeito que a partir do trabalho de memória desdobra questões sobre o artefato fotográfico e então constrói novos significados, tanto para si como para outros que terão acesso ao produto final de seu trabalho. De modo aproximado, também as exposições que no tempo presente tem dado a ver as fotografias de Recife realizadas por Lacerda se orientam por caminhos similares ao tencionar o documento, a memória e a identidade. Nesse sentido, a fotografia de Alcir Lacerda pode ser observada em diacronia: as transformações dos espaços, relações e sujeitos retratados pela experiência do olhar.

\section{Referências bibliográficas}

AMORIM, Luiz. Obituário arquitetônico: Pernambuco Modernista. Recife: Editora UFPE, 2007.

BRUCE, Fabiana. Caminhando numa cidade de luz e sombras - a fotografia moderna no Recife na década de 1950. Recife: Editora Massangana, 2014.

BRUCE, Fabiana. O álbum de Berzin. Recife: Cepe, 2012.

CIDADE, Daniela Mendes. A cidade revelada: a fotografia como prática de assimilação da arquitetura. Dissertação de Mestrado em Teoria, História e Crítica da arquitetura. Universidade Federal do Rio Grande do Sul. Faculdade de Arquitetura. Programa de Pós-Graduação em Arquitetura. Porto Alegre, RS -2002.

LE GOFF, Jacques. História e memória. 4.ed. Campinas: Editora da Unicamp, 1996.

LORETTO, Rosane Piccolo. Paraíso e Martírios: histórias de destruição de artefatos urbanos e arquitetônicos no Recife. Dissertação (Mestrado em Desenvolvimento Urbano). Recife: UFPE. Programa de Pós-Graduação em Desenvolvimento Urbano, 2008.

\begin{tabular}{l|lll} 
VOL. 3 & N.6 I IL/DEZ. 2017
\end{tabular} 
MALTA, Albertina Ótavia Lacerda (org). Alcir Lacerda: fotografia. Recife: Cepe, 2012.

MALTA, Albertina Lacerda. A Coleção Alcir Lacerda, um testemunho da história. Revista Coletiva, $\mathrm{n}^{\circ} 12$, set-dez/2013.

MAUAD, Ana Maria. Itinerários da memória - práticas fotográficas, trajetórias profissionais e os sentidos da história. Nuevo Mundo Mundos Nuevos [En línea], Imágenes, memorias y sonidos, Puesto en línea el 13 junio 2012. Disponível em < http://nuevomundo.revues.org/63139>.

MAUAD, Ana. Os fatos e suas fotos: dispositivos modernos na produção do acontecimento na contemporaneidade. Z Cultural - Revista Virtual do Programa de Avançado de Cultura Contemporânea (UFRJ), v.IV, p.1-8, 2008.

MAUAD, Ana. Visões plurais em um único olhar: A experiência fotográfica de Marcel Gautherot, 1940-1960. Anais do Museu Paulista, vol.16 no.2 São Paulo July/Dec. 2008.

MAUAD, Ana Maria. Poses e Flagrantes: Ensaios sobre História e Fotografia. Niterói: Editora da UFF, 2008.

MONTEIRO, Charles. História, fotografia e cidade: reflexões teórico-metodológicas sobre o campo de pesquisa. MÉTIS: história \& cultura - v.5. n.9, p.11-23, jan./jun.2006.

NORA, Pierre. Entre memória e história: a problemática dos lugares. Projeto História, n.10, p. 7-28, 1993.

POSSAMAI, Zita Rosane. Cidade fotografada: memória e esquecimento nos álbuns fotográficos - Porto Alegre, décadas de 1920 e 1930. Tese (Doutorado em História). Porto Alegre: UFRS. Programa de Pós-Graduação em História, 2005.

ROUILLÉ, ANDRÉ. A fotografia entre documento e arte contemporânea. Tradução Constância Egrejas. São Paulo: Editora Senac, 2009.

VELHO, Gilberto. PROJETO E METAMORFOSE. Antropologia das Sociedades Complexas. Rio de Janeiro: Jorge Zahar Editor, 1994.

\begin{tabular}{l|l|l|l} 
VOL. 3 & N.6 IUL/DEZ. 2017
\end{tabular} 